\title{
Investigating the hindrances of implementation of Occupational Health and Safety among Small Medium Enterprise's in the Gauteng Province of South Africa.
}

\author{
Nokulunga X Mashwama ${ }^{\mathrm{a}}$, Hildah Kale ${ }^{\mathrm{b}}$, Prof C.O Aigbavboa ${ }^{\mathrm{c}, *}$ \\ University of johannesburg, Department of Construction and Quantity surveyin, Faculty of Engineering \& the Built Envireonment,Johannesburg, \\ 2028, South Africa ${ }^{a, b, c}$
}

\begin{abstract}
A positive safety culture requires participation of all stakeholders in construction industry, and is shown through the safety-related knowledge, attitudes, beliefs, behaviour and practices of each worker. Therefore, the study is investigating the hindrances in the implementation of occupational health and safety (OHS) among small medium enterprises (SME'S) in the construction industry in the Gauteng Province of South Africa. A structured questionnaire was distributed to different construction companies and construction workers. From the 70 questionnaires distributed, 42 were brought back and they were all valid and usable. Findings from the survey results obtained from the chosen respondents revealed health safety was known and practiced, however, there are hindrances in the implementation such as poor regular inspections and audits, poor management, poor supervision, lack of material and components, lack of management commitment, equipment and tools, poor communication between workers, poor employers involvement, lack of training and risk education to name a few were the major hindrance in the implementation of occupational health and safety among SME's. Furthermore, if the challenges could be addressed appropriate and effectively result could manifest such as increased productivity; improve quality work; contractors growth and reduced claims; reduced accidents; reduced rework; improved schedule performance. Management and leadership at all levels are therefore encourage to improve construction OH\&S in South Africa among SME's. Moreover, occupational health and safety of the workers is not negotiable, is all pervasive, increases productivity, and leads to better performance, improve the company image, reduced claims and accidents also reduce lost times spent on injuries. The concept of OHS implementation must be emphasized by the client and the consulting team by way of having occasional not once off, a major workshop to be held three times in a year, to increase the awareness and the seriousness of the implementation of OHS.
\end{abstract}

(C) 2018 The Authors. Published by Diamond Congress Ltd., Budapest University of Technology and Economics Peer-review under responsibility of the scientific committee of the Creative Construction Conference 2018.

Keywords: occupational health and safety, small and medium enterprises, south africa.

\section{Introduction}

According to [1], the construction industry creates employment and serves as a means of generating income for many people and also as a means of application of technologies in various degrees. Therefore, the sector engages about 240000 workers in South Africa thus contributing significantly to the gross domestic product (GDP) [2]. Nonetheless, the construction industry can be interlinked with the economy of a country and this often is an indicator of how healthy the state of the said economy is. Therefore, if the construction sector and the economy of a country are linked, it is necessary for the sector to effectively attend to the welfare of the workers in that industry [3]. Moreover the sector is associated with high risks particularly for workers nonetheless its importance in the social and economic development in South Africa [4; 5]. [6] Reported that the construction industry has great number of injury and fatality among workers 
and this is substantiated by the [7] that many construction workers become unfit at one point or the other as a result of minor injuries or some kind of problems in their health.

Health and Safety (H\&S) is the responsibility of everyone at work, construction companies have to be aware that they are responsible for managing and improving issues related to $H \& S$ on construction sites [8]. This is because construction, to a large extent, is a labour intensive industry and depends on the availability and safety of workers to complete current and future projects [9]. Despite refined H \&S regulations in most countries, high rates of accidents and fatality persist. The regulations and procedures intended to prevent such accidents are usually mandated by the appropriate occupational safety authority in each country [10]. The academics and professionals within the construction industry believe that regulations and legislation on their own cannot achieve the desired goal of zero accidents and incidents on construction sites, but the latter can be achieved with the involvement of the stakeholders in the industry [11]. Adherence to regulations and legislation is not the only way to ensure safety on the working environment however it provides a basis for the employment and enforcement of good construction practices at minimal cost [11]. Issues such as injuries, fatalities, and delays, financial losses can result as result of poor regulations and standards in a construction work environment $[9 ; 10]$.

[12] Promotes the establishment of a workplace that minimizes active risks and hazards, and emphasis the implementation of mitigating factors to either reduce or eliminate these risks and hazards. [13] Identified that productivity and quality, which are vital elements of the value chain on a construction site, are negatively affected by poor health and safety implementation. Construction workplaces are potentially seen to be the most risky and a place where accident are common. Therefore, workers are at the risk of injury and in extreme cases death, if their exposure to construction sites is not controlled [14]. According to [9], construction is described as a "dangerous, risky and hazardous task, to emphasize the above statement the United Kingdom;[15], agreed that in the last twenty-five years alone over 2800 construction workers have died due to construction accidents, with even more workers having suffered from serious injuries. "This is an unacceptably high figure and the industry needs to devise proper solutions to these problems" [15]. For many years, construction has consistently been among those industries with the highest injury and fatality rates [9]. In theory, most construction injuries sustained on site can be prevented or controlled. Unfortunately, this goal became unachievable and compliance among the stakeholders has been very inactive [16]. Prevention and control of risk in construction industry is a consistence global challenge, construction have been considered having the worst safety records among its diverse economic sectors of its kind. In addition to the loss of life and reduction in the quality of life of construction workers, construction incidents lead to project delays, increase project cost, medical burden, and other negative consequences [17].

\section{Occupational health and safety in South Africa}

Worldwide construction industry contributes a large number of injuries [18;10]. However, construction in developing countries, including South Africa, performs worse than construction in developed countries [18]. Furthermore, there is a high level of non-compliance with H\&S regulations in South Africa. Previous research findings indicated that, at the organisational and site level, this poor performance in construction H\&S is attributable to a lack of management commitment, inadequate supervision, and inadequate or lack of H\&S training [18]. Moreover, a lack of worker involvement, personal risk appreciation and work pressures also contribute to poor implementation of health and safety. Management and leadership at all levels are therefore important to improve construction H\&S in South Africa. Leadership needs to manifest itself among all the stakeholders, commencing with clients and including project managers, designers, quantity surveyors, contractors, manufacturers and suppliers [19].

The cost of an accident (CoA) contributes substantially to the cost of construction, which in turn creates a financial motivator for all stakeholders (including clients) to address H\&S. However, a pre-occupation with cost, quality and time by stakeholders marginalises the potential realisation of the benefits of optimum H\&S in the form of enhanced overall performance $[20 ; 21 \& 23]$. The high level of non-compliance in building construction indicates that there is a lack of understanding and appreciation for the synergistic role of H\&S and ultimately, a business case for H\&S. Internationally and in South Africa, poor H\&S implementation is often attributed to a lack of respect for workers in the building construction industry in which the workforce is treated as a low-value transient resource with little investment in their development and insufficient attention to their welfare [21;23]. An understanding of construction $\mathrm{H} \& \mathrm{~S}$ is handicapped by lack of available statistics, and in particular that from the Compensation Commissioner. The 1999 statistics [18; $20 \& 21]$ indicated that the construction industry accounts for around the third highest number of fatalities per 100000 workers, and the ninth highest number of permanent disabilities per 100000 workers. The fatality 
rate in the construction industry is approximately 20 per 100000 workers, or approximately 150 fatalities per year excluding construction-related motor vehicle accidents, Motor vehicle accidents account for approximately another 100 fatalities per year [21\&23].

The high rate of non-compliance with the requirements of the Construction Regulations, which amounted to $50 \%$ of construction sites, indicates that H\&S in the construction industry in South Africa lags significantly behind compared to other developed countries. The construction industry currently has the third highest prevalence of HIV positive workers [21] and the industry faces an increasing loss in workdays due to absenteeism and reduction in productivity, skills shortages and increased costs of construction due to rising overheads. The CoA is estimated to be around $5 \%$ of the value of construction costs which is ultimately passed onto clients. Moreover, inadequate H\&S or a lack thereof negatively affects other project parameters such as productivity [19]. The global poor H\&S performance recorded in the construction industry has resulted in H\&S regulations being subjected to major revisions during the last three decades [18].

The primary objective of any H\&S legislation is the prevention of accidents and their consequences in terms of injury, disablement and fatality, and ill health within the work environment. The achievement of this objective depends on good legislation supported by effective, sensible and accountable enforcement [21;24 \&25]. The introduction of H\&S legislation in member states of the European Community was accompanied by enforcement of the legislation, which highlighted high levels of noncompliance with more than half of the sites being shut down in Portugal [26; \&27]. After 1994 the government of South Africa was confronted with the dual challenge of reintegrating the country into the global economy as well as positioning itself to deal with the challenges of the new democratic order $[21 ; 22$; $28 \& 29]$. With the objectives of economic growth in mind, the government started promoting the development of SMMEs. The main objectives were to generate employment, redistribute income and become globally competitive [30].

\section{Small and Medium Enterprises (SME's) contractors in South Africa}

The growing importance of SMEs is clear, and SMEs currently account for about half of all people in formal employment in South Africa. This is a remarkable achievement, given the restrictions entrepreneurs face in this country, namely the real regulatory. As indicated in the report of the 2004 SME survey led by [22 \& 23], SMEs in South Africa are alive, well and regard themselves as highly competitive. However, few SME owners give the government credit for their initiatives and efforts to promote SMEs. [22] States that given the amount of resources being ploughed into SME development, the situation reflects poor communication rather than poor strategy. The survey also shows that less than half of the SME owners were positive about legislation, the impact of skills development programmes and the impact of BEE, the latter having more negative than positive scores. A low $12 \%$ positive rating was given for the impact of general government incentives for SMEs [28; 29\& 30]. Because of the many neutral responses (a quarter to a third) on most issues, government has an opportunity to use communications to change perceptions [22;28;29\&30].

The lack of sufficient capital and credit is often a major handicap in the development of SMEs, especially in their growth stages. In developing countries worldwide, close to $95 \%$ of all SMEs have to rely solely on the personal resources and initiatives of the owners [22 \&24]. The existence of a cheap source of labour, combined with the low socio-economic status of workers are major obstacles to improving OH\&S as this limits workers' capacity to resist working under poor $\mathrm{OH} \& \mathrm{~S}$ conditions on sites [29 \&30]. Low skill levels linked with the adoption of labour intensive methods by the construction industry in South Africa and many other developing countries means managing OH\&S can be challenging. It is clear that changing the attitudes of SMEs in construction must be handled to ensure workers' rights are not flagrantly abused in an industry setting where large numbers of the labour force are unskilled and largely uneducated [22;24 \&30].

SMEs do not create better quality jobs than large enterprises [31]. SMEs are usually created as a last resort and not as a first choice of employment and therefore have limited growth potential [22]. Evidence is also inconclusive about SMEs being more innovative than large firms. It is said that large companies may exploit economies of scale and more easily undertake the fixed cost associated with research and development [31]. All in all, many authors such as [22;26;27 \&31] reported on the importance of SMEs and that small business was seen as the essential condition for economic growth. In contrast, different role players are offering assistance in many areas, there are still many failures. This indicates that the type of assistance is inadequate, irrelevant or not given when needed. [1], in their research using 
Kenya as a case study, found that the safety of construction workers within the SME 's organisation was not given urgent attention on most construction sites. Workers on a construction site are at risk of being injured by construction equipment, while carrying out their tasks, or they could be injured if safety procedures are not adhered to. There is no guarantee that construction workers will not be injured on a project [23]. The best that can be achieved is to minimise possible injuries or deaths by posting safety procedures around the construction site so as to assist in the implementation of occupational health and safety [32 \&22].

\section{Hindrances of implementing OHS among SME's}

Presently, SME owners in South Africa have numerous challenges to overcome. [22; 23; 28; 30\&31]compiled the following list of most burning issues that business owners face today:

- A lack of business skills, this is because of a poor education system and little or no culture of entrepreneurship;

- A lack of finance, financial institutions will only lend money to low-risk clients and the cost of banking is high;

- $\quad$ High costs, the cost of raw materials and telecommunications is high;

- $\quad$ Poor skills of employees, the government skills development system is not assisting SMEs;

- Bargaining councils, they have become huge conspiracies in which smaller businesses are crushed; the CCMA, time is wasted because employees can take their employers there for the smallest whim;

- The black economic empowerment; businesses are still confused by the multitude of criteria set out in the codes.

- Many owners also pay consultants huge sums of money to obtain ratings they do not yet require;

- Crime;

- $\quad$ Stock theft as an example; obviously has a negative effect on some of the SMEs;

- $\quad$ Exposure; the business owners do not portray themselves well.

\section{Challenges faced by SME,s}

The following concerns about the growth and development of SMEs were identified by [21;22 \&31]

- Ownership constraints are particularly severe for entrepreneurs (especially women) in rural areas.

- Low-wage competition is discouraged by legislation, thereby discouraging labour intensive activity.

- There is a small customer base.

- Interest rates are high and there is limited or no access to capital.

- There are insufficient government contracts and weak support programmes.

- International trade is limited.

- $\quad$ Plans and technology are outdated and management skills are inadequate resulting in poor management.

\section{Methodology}

\subsection{Research approach and design}

Quantitative approach method was used to collect data for the study. A quantitative research is an enquiry into an identified problem, measured with numbers, and analysed using statistical techniques. The goal is to determine whether the predictive generalizations of a theory hold true. Much research in the engineering and management sphere involve asking and obtaining answers to questions through conducting surveys of people by use of structured questionnaires, interviews and observations. The study utilised questionnaires to collect data and answer the objective of the study which was to investigate the hindrances of implementation of health and safety among SME's in the Gauteng Province of South Africa. The study was carried out in Gauteng Province of Republic of South Africa, specifically on the Johannesburg areas, on small and medium enterprises (SME's) contractors. The target population were the owners and managers of SME's in Johannesburg Metropolitan Municipality. The reason for choosing owners and managers was that, they can offer useful information on the occupational health and safety challenges among SME's contractors in the construction industry of South Africa.

\subsection{Analysis}

In this study, the analysis employed simple statistical methodology, which is descriptive statistics (mean, mode, median, number, percentage, range, standard deviations). Respondent were required to respond to question based on 
the five point likert scale. The Likert scale was used because it allows a range of responses to be generated including neutral answers and does not force a decision as in the case of "yes" or "no" type of questions. The mean item score was adopted to rank the factors from highest to lowest. The Mean Item Score (MIS) is expressed and calculated for each item as follows:

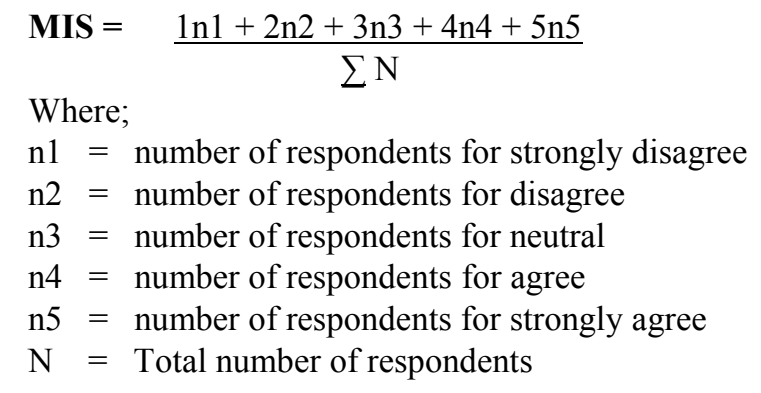

\section{Findings and discussions}

\subsection{Level of implementation of OHS in SME's contractors}

Respondents were asked to state the level of implementation of OHS among the SME's, about $33 \%$ of the responded felt that it was practiced between $60-70 \%, 31 \%$ of the respondent believed that it was practiced between $80-90 \%, 24 \%$ between the range of $30-50 \%$ and $12 \%$ between the range of $90-100 \%$.

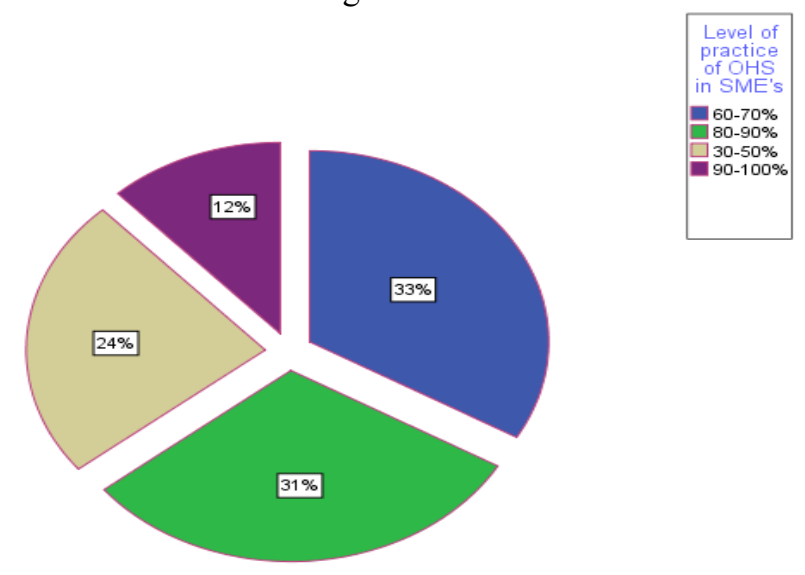

Figure 7: Level of implementation of OHS in SME'S

\subsection{Hindrances of OHS implementation by SME's}

Respondent were asked to rank the factors that hinder the success implementation of OHS among SME's contractors, The responded rank lack of regular inspections and audits the highest with a MIS $=4.40$ and STD $=.964$; poor management/supervision/information flow; Material and components was ranked 2 with a MIS=4.31 and $\mathrm{STD}=0.924$ and 1.047 respectively; lack of management commitment was ranked 3 with MIS=4.29 and STD $=0.970$; Equipment and tools was ranked 4 with and $\mathrm{MIS}=4.21$ and $\mathrm{STD}=0.976$; lack of communication between workers was ranked $5^{\text {th }}$ with MIS $=4.17$ and STD 0.853; poor employees involvement was ranked $6^{\text {th }}$ with $\mathrm{MIS}=4.14$ and $\mathrm{STD}=1.049$; lack of training and risk education was ranked $7^{\text {th }}$, with $\mathrm{MIS}=4.12$ and $\mathrm{STD}=1.109$; lack of skilled workforce was ranked 8 with $\mathrm{MIS}=4.10$ and $\mathrm{STD}=0.983$; work area access was ranked $9^{\text {th }}$ with $\mathrm{MIS}=4.02$ and $\mathrm{STD}=1.024$; poor work/jobsite conditions ranked $10^{\text {th }}$ with $\mathrm{MIS}=3.98$ and $\mathrm{STD}=0.924$; subcontractors involvement was ranked 11 with MIS=3.95 and STD=1.147; lack of incentive for good performance was ranked 12 with MIS=3.93 and $\mathrm{STD}=1.135$; investigations and risk assessments was ranked $13^{\text {th }}$ with $\mathrm{MIS}=3.83$ and $\mathrm{STD}=1.208$.

Table 1: Implementation level

\begin{tabular}{|l|c|c|c|}
\hline Descriptive Statistics & MIS & Std. Deviation & Rank \\
\hline Lack of regular inspections and audits & 4.40 & .964 & 1 \\
\hline Poor management/supervision/information flow & 4.31 & .924 & 2 \\
\hline
\end{tabular}




\begin{tabular}{|l|c|c|c|}
\hline Material and components & 4.31 & 1.047 & 2 \\
\hline Lack of management commitment & 4.29 & .970 & 3 \\
\hline Equipment and tools & 4.21 & .976 & 4 \\
\hline Lack of good communication between workers & 4.17 & .853 & 5 \\
\hline Poor employees involvement & 4.14 & 1.049 & 6 \\
\hline Lack of training and risk education & 4.12 & 1.109 & 7 \\
\hline Lack of skilled workforce & 4.10 & .983 & 8 \\
\hline Work area access & 4.02 & 1.024 & 9 \\
\hline Poor work/jobsite conditions & 3.98 & .924 & 10 \\
\hline Subcontractors involvement & 3.95 & 1.147 & 11 \\
\hline Incentive for good performance & 3.93 & 1.135 & 12 \\
\hline Investigations and risk assessments & 3.83 & 1.208 & 13 \\
\hline
\end{tabular}

Table 2 below shows the benefit of Occupational health and safety implementation in SME's contractor. Where the responded ranked $1^{\text {st }}$ Reduce lost times spent on injuries with $\mathrm{MIS}=4.26$; $\mathrm{STD}=0.828$; Avoid threat of legal action or prosecution and ; Increase productivity was ranked 2 with $\mathrm{MIS}=4.19$ and $\mathrm{STD}=0.804 ; 0.634$ respectively; Improve quality work was ranked no. 3 with $\mathrm{MIS}=4.17, \mathrm{STD}=0.537$; Implementation contributes contractors growth and Improve relationship between contractors and workers was ranked $4^{\text {th }}$ with $\mathrm{MIS}=4.05$ and $\mathrm{STD}=0.764 \& 0.795$ respectively; Reduced claims was ranked 5 with $\mathrm{MIS}=4.02$, STD $=0.924$; Reduces accidents was ranked 6 with MIS $=4.00$ and STD $=0.883$; Motivate health workers; Improved employee job satisfaction and Reduced rework were ranked 7 with $\mathrm{MIS}=3.95$ and $\mathrm{STD}=0.936$ and 0.987 respectively; Better chances in bidding process was ranked $8^{\text {th }}$ with MIS=3.90 and $\mathrm{STD}=0.983$; Improves schedule performance was ranked 9 with MIS=3.74 and $\mathrm{STD}=0.828$ and Lower employee turnover was ranked $10^{\text {th }}$ with $\mathrm{MIS}=3.33$ and $\mathrm{STD}=1.141$

\begin{tabular}{|c|c|c|c|}
\hline Benefits & MIS & Std. Deviation & Rank \\
\hline Reduce lost times spent on injuries and properly loss & 4.26 & .828 & 1 \\
\hline Avoid threat of legal action or prosecution & 4.19 & .804 & 2 \\
\hline Increase productivity & 4.19 & .634 & 2 \\
\hline Improve quality work & 4.17 & .537 & 3 \\
\hline Implementation contributes contractors growth & 4.05 & .764 & 4 \\
\hline Improve relationship between contractors and workers & 4.05 & .795 & 4 \\
\hline Reduced claims & 4.02 & .924 & 5 \\
\hline Reduces accidents & 4.00 & .883 & 6 \\
\hline Motivate health workers & 3.95 & .936 & 7 \\
\hline Improved employee job satisfaction & 3.95 & .936 & 7 \\
\hline Reduced rework & 3.95 & .987 & 7 \\
\hline Better chances in bidding process & 3.90 & .983 & 8 \\
\hline Improves schedule performance & 3.74 & .828 & 9 \\
\hline Lower employee turnover & 3.33 & 1.141 & 10 \\
\hline
\end{tabular}

\section{Conclusion}

The Findings of this study presented the factors that hinder the success implementation of OHS among SME,s to be lack of communication, lack of management commitment lack of regular inspections and audits; poor management/supervision/information flow; lack of management commitment; Equipment and tools; lack of communication between workers; poor employees involvement; lack of training and risk education; lack of skilled 
workforce; poor work/jobsite conditions. Furthermore, if the challenges could be addressed appropriate and effectively result could manifest such as increased productivity; improve quality work; contractors growth and reduced claims; reduced accidents; reduced rework; improved schedule performance. Management and leadership at all levels are therefore encourage to improve construction OH\&S in South Africa among SME's. Moreover, occupational health and safety of the workers is not negotiable, is all pervasive, increases productivity, and leads to better performance, improve the company image, reduced claims and accidents also reduce lost times spent on injuries.

\section{Recommendations}

The concept of OHS implementation must be emphasized by the client and the consulting team by way of having occasional not once off, a major workshop to be held three times in a year, to increase the awareness and the seriousness of the implementation of OHS.

\section{References}

[1]Mitullah, W. V \& Wachira, I. N. (2003).Informal Labour in the Construction Industry in Kenya: A Case Study of Nairobi. Sectorial Activities Programme A 100 20499 999. ILO, Geneva.

[2]Ramutloa, L. 2007. Department of Labour Republic of South Africa, Amended Occupational Health and Safety Act. (2007) 2-27.

[3]James, P. M., Braam rust, A. A. \& Kingma, L. (2012). The well-being of workers in the South African construction industry: A model for employment assistance Cape Peninsula University of Technology.

[4]Brace, C.L. \& Gibb, A. G.F. (2005). A health management process for the construction industry: In: Haupt, $\mathrm{T}$ and Smallwood, J. (Eds.) Rethinking and revitalizing Construction safety, health and quality. Port Elizabeth, South Africa.

[5]James, P. M., Braam rust, A. A., \& Kingman, L. (2011). The well-being of workers in the South African construction industry: A model for employment assistance, African Journal of Business Management Vol. 6(4), pp. 1553-1558.

[6]Cooper, B \& Schaffer, J. 2010.Construction Site Falls: Pennsylvania or New jersey construction accident Published by Cooper \& Schaffer, LLC 2012.

[7]Chartered institute of building. 2008. Health and Safety in the Construction Industry. CIOB supports a zero tolerance approach to unsafe and unhealthy practices [Online] Available from: http://www.hse.gov.uk/humanfactors/comah/common. [Accessed: 09/06/2017].

[8]Davies, V. J. \& Tomasin, K.(2000) Construction Safety Handbook: Hardcover, 303 Kurasa, Kuchapishwa 1996 n.a Thomas Telford Ltd .

[9]Haupt, T C. (2001). The Performance approach to construction worker safety and health: PhD. Dissertation, University of Florida, Florida.

[10]Gee, A.F. and Saito, K. (2000). Construction Loads and Other Safety Measures Specified by U.S., U.K. and Japanese Bridge Standards: In: Ratay, R.T.(ed.), Construction Safety Affected by Codes and Standards, Proceedings of a session sponsored by the Design Loads on Structures During Construction Standards Committee and the Performance of Structures During Construction Technical Committee of the Structural Engineering Institute, Minneapolis.

[11]Ratay, R. T. (2001) Structural Condition Assessment: For Serviceability, Rehabilitation, Retrofitting, Adaptive Reuse, Code Compliance, And Vulnerability. (2005) 5-8.

[12]Occupational safety and health administration. (2012). Construction Safety and Health: Fall Hazard Participant Guide. U.S. Department of Labour SH16586-07-06-F-36.

[13]Smallwood, J. J. (2004). The influence of engineering design on health and safety during construction: Journal of the South African Institute of Civil Engineering, Vol. 46 , no. 1, pp.2-8. 
[14]Hunter, C.M. (2011).Six Construction Site Hazards, Construction Induction, Construction Safety, Construction safety images. Riskex.

[15]Health and safety executive. 2009. A technical guide to the selection and use of fall prevention and arrest equipment, Author: Cameron, L., Duff, $\mathrm{R}$ and Gillan, G. Published by Glasgow Caledonian University.

[16]Gambatese, J. A \& McManus, J. F. 1999. Discussion of the constructability review process: a constructor's perspective, by Roy Mendelssohn, Journal of Management in Engineering, 15(1) p93-94.

[17]Ahassan, R. (2001). "Legacy of implementing industrial health and safety in developing countries." J. Physiol. Anthropology and Appl. Human Sci., 20(6), 311-319.

[18]Department of Labour. (2011). Occupational Health and Safety (OH\&S) Inspectorate in relation to the construction industry. Government Gazette 539 (2010) 33176.

[19]Health and safety executive. (2012). Top tips for ladder and stepladder safety: An employer's ‘Guide INDG405 HSE Books (ISBN 071766105 9).

[20]Hsiao, H. \& Armstrong, T. J. (2012). Preface to the special section on occupational fall prevention and protection: National Institute for Occupational Safety and Health (NIOSH). Hum Factors 2012 Jun; 54(3):301-302.

[21] CIDB, (2011), SME's development, www.info.gov.za/view/downlaodfileAction?id=68205 (accessed January 2017).

[22] Yanta, T. (2001). "Local government supporting or stunting SMME growth? University of Natal, Center for Applied and social science". Indicator South Africa barometer trend. 18(2), 44-48.

[23] Kashiwagi \& Khiyara, (2002). The optimization of value engineering as a structured component of the construction procurement process. Performance based studies research group, Arizona State Univesity, USA.

[24] Monks, P. (2010). Suistanable growth of SME's. Unpublished masters research report, Nelson Mandela Metropolitain University.

[25] Marx, H.J, (2011). “CIDB Indicators" an international Journal. 1.93-117.

[26] Strydom, J; Jooste, C. and Cant, M. (2000). Marketing Management (4 $4^{\text {th }}$ Ed). Pub Juda \& co ltd,University of Cape Town.

[27] Raymond, Y.C; Love, P and Edwards, D (2002), "Time-cost relationship in Australian building construction project. Journal construction Engineering and Management. 13(2) 187-194.

[28] Fakoki, O. (2010). Obstacles to the growth of SME's in South Africa. A principal component analysis approach. Doctoral Thesis, University of Forte Hare South Africa.

[29] Lunsche, S. (2010). The quite death-where to next for South Africa economic policy, Wits business school university of Witwatersrand, Johannesburg.

[30] Jooste, C. (2012). South African transition to consolidated budget. South African Journal of economics. 80(2) 181-199.

[31] Audet and Courteret, (2012). Coaching the entrepreneur, features and success factors. Journal of small business enterprise and development. 19 (1) 515-531

[32] Boris and Naidoo.(2010). Business sustainability: empirical evidence on operational skills in SME's in South Africa: Journal of small business enterprise and development. 19(1) 146-163

[33]Hinze, J \& Huang, X. (2003).Analysis of Construction Worker Fall Accidents: Journal of Construction Engineering and Management. ASCE MAY/JUNE 2003.

[34]Hinze, J. (2005). Construction Accidents: Journal of Construction Engineering and Management ASCE. May/June 2005.

[35]Howarth, T. \& Watson, P. (2007). Construction Safety Management: Construction safety management, Enforcement of the Health and Safety. United Kingdom. 